\title{
Dopaminergic Modulation of Physiological and Pathological Neurohumoral Activation in Man
}

\author{
Andries J. Smit *,**, Aloysius G. Lieverse*, Dirk Jan van Veldhuisen ${ }^{* *}$, \\ and Armand R.J. Girbes ${ }^{* * *}$
}

\begin{abstract}
Close relations exist between the peripheral dopaminergic system, and the sympathetic nervous and renin-angiotensin-aldosterone system: D1 dopamine receptor stimulation-induced vasodilation may activate the sympathetic nervous and renin-angiotensin system in vivo, presynaptic D2 dopamine receptor stimulation is known to inhibit stimulated norepinephrine release from sympathetic nerve terminals, in experimental conditions both in vitro and in vivo. Endogenous dopamine has a tonic inhibitory effect on aldosterone release. Conversely, basal sympathetic activity has been found to be required for the natriuretic effect of dopamine in proximal renal tubules. Other relations include the conversion of dopamine to other catecholamines, and co-release. This review considers the reflection of some of these relations and their clinical significance in man in physiological and pathophysiological conditions, especially congestive heart failure. An inhibitory effect of the nonselective dopamine agonist ibopamine on plasma norepinephrine levels was found in normal man during exercise but not at rest, and in patients with several degrees of congestive heart failure, both at rest and during exercise. Infusions of dopamine 1 $\mu \mathrm{g} / \mathrm{kg} / \mathrm{min}$, but not $3 \mu \mathrm{g} / \mathrm{kg} / \mathrm{min}$ were found to lower plasma norepinephrine levels during sympathetic stimulation by exercise or by a cold pressor test in normal man. Dopamine antagonists enhance the rise in plasma norepinephrine levels during exercise, indicating that endogenous dopamine also inhibits norepinephrine release. Both phentolamine and prazosin abolish the natriuretic effects of dopamine in man, even when the renal hemodynamic effect of dopamine is unaffected. In conclusion, it is important to be aware of clinically significant interactions between the peripheral dopaminergic and sympathetic nervous system at different levels. (Hypertens Res 1995; 18 Suppl. I: S107-S111)
\end{abstract}

Key Words: dopamine, norepinephrine, congestive heart failure

Stimulation of presynaptic D2 dopamine receptors inhibits noradrenaline (NE) release during sympathetic activation. In recent years, Rump $(1,2)$ demonstrated a fall in stimulation-induced norepinephrine release from human kidney slices with relatively low doses of the highly selective D2 dopamine agonist carmoxirole. This effect of carmoxirole was inhibited by sulpiride, but not by the selective D1 dopamine receptor antagonist Sch 23390 , or by phentolamine. He found comparable results for quinpirole and lower doses of carmoxirole, but fenoldopam, instead, enhanced norepinephrine release. These results illustrate the often opposite effects of D1 and D2 dopamine receptor agonism. Both experimental and clinical studies have shown that D1 dopamine receptor agonists may increase norepinephrine release, or plasma norepinephrine levels $(3,4)$. On the other hand, for D2 dopamine agonists experimental studies have provided conclusive evidence that the in vitro inhibitory effect is also operative under in vivo conditions. Szabo (5) demonstrated that quinpirole inhibited renal norepinephrine spillover in anaesthetized rabbits. He used labeled norepinephrine infusions, and so could exclude neuronal or extraneuronal norepinephrine uptake. He also measured renal sympathetic nerve activity (RSNA) at the same time. The firing rate was increased during quinpirole. The ratio of renal NE spillover and RSNA firing rate is drastically lowered during quinpirole. This indicates that the released amount of norepinephrine per action potential in postganglionic nerves is reduced. Other recent experimental studies by Roquebert (6), and by Carratu (7), essentially confirmed the prejunctional inhibition of sympathetic neurotransmission. In man, several authors, e.g. Carey et al. (8), and several others, found after initial reports by Ziegler et al. (9) in the seventies, that bromocriptine suppresses basal and stimulated noradrenergic activity in man $(10,11)$. Additional evidence that endogenous dopamine also affects plasma norepinephrine levels in man was provided by a study of Mannelli et al. (12), who reported on the use of the D2 dopamine antagonist domperidone in an exercise test in humans. Domperidone was shown to enhance the rise in plasma norepinephrine levels which occurs

From the ${ }^{*}$ Department of Medicine, ${ }^{* *}$ Department of Cardiology, and ${ }^{* * *}$ Division of Intensive Care, the Department of Surgery, University Hospital Groningen, Groningen, The Netherlands.

Address for Reprints: Andries J. Smit, Department of Medicine LM3, University Hospital Groningen, Oostersingel 59, 9713 EZ Groningen, The Netherlands. 
during exercise. So, indirect evidence exists that the presynaptic D2 dopaminergic effect can be observed in man under physiological conditions provided that the sympathetic nervous system (SNS) is stimulated. Circulating free dopamine levels are very low, endogenous dopamine modulates noradrenaline release in sympathetic nerves probably as neuronal dopamine which may be coreleased with norepinephrine in the synaptic cleft. Similarly, adrenal medullary dopamine is coreleased with norepinephrine or epinephrine. Administration of exogenous dopamine results in high circulating levels of free dopamine and may then activate presynaptic D2 dopamine receptors. The same holds for dopamine agonists.

Little is known about the clinical relevance of this dopaminergic property under pathophysiological conditions. In the following we review some of our studies addressing this relation between dopamine and the sympathetic nervous system, epecially in patients with congestive heart failure. However, some of the studies also concern the effects of dopaminergic stimulation in man on the renin angiotensin aldosterone system, and conversely, the effects of alpha-blockade on the renal effects of dopamine.

\section{Methods}

Studies were performed either in healthy volunteers or in patients with several degrees of congestive heart failure. One study was performed in patients with chronic mild to moderate renal failure. All studies were approved by the ethical committee of our hospital, the subjects gave informed consent. The studies were performed according to the rules given in the Declaration of Helsinki, 1964, and the Declaration of Tokyo, 1975. Exercise studies were performed after fasting for at least $3 \mathrm{~h}$, none of the volunteers or patients had participated in formal exercise training during the preceding year. For the exercise studies, on a first occasion the maximal oxygen consumption $\left(\mathrm{VO}_{2} \max \right)$ was determined. The exercise tests were done by graded increasing of the exercise load until exhaustion by a bicycle ergometer test. The workload was started at $75 \mathrm{~W}$ and was increased every $3 \mathrm{~min}$ by $25 \mathrm{~W}$. The volume of inspired air, and the percentage $\mathrm{CO}_{2}$ and $\mathrm{O}_{2}$ of the expired air were measured using an ErgoOxyscreen apparatus (E. Jaeger Medical Electronic Plant, Hoechberg/Wuerzburg). For resting plasma norepinephrine levels, blood samples were drawn from an intravenous canula in an antebrachial vein, inserted at least half an hour before, and after at least $20 \mathrm{~min}$ of rest. During the exercise test samples were drawn at the end of each exercise step. Blood pressure was determined at least every 30 min according to Riva-Rocci-Korotkoff using an automatic device (E. Jaeger Medical Electronic Plant, Hoechberg/Wuerzburg) during exercise tests, or using an automated oscillometric blood pressure device (Spacelabs 90207). Plasma norepinephrine levels were determined by HPLC with electrochemical detection, after an extraction procedure according to Smedes et al. (13). The intra-assay coefficient of variation was $4.2 \%$ for norepinephrine. All data unless otherwise mentioned are given as means $+/-\mathrm{SD}$. Paired statistics were calculated for differences between study days, they were considered statistically significant at the $5 \%$ level.

\section{Results and Discussion}

Using the aselective dopamine agonist ibopamine Girbes et al. $(14,15)$ found an inhibitory effect of ibopamine on the rise in plasma norepinephrine levels during exercise but not at rest in normal man. Dopamine agonists are mainly used in the chronic treatment of congestive heart failure. However, little is known of the clinical relevance of this dopaminergic effect under pathological conditions. In patients with severe congestive heart failure, van Veldhuisen et al. (16) showed that chronic treatment with ibopamine, given during 6 weeks, did lower resting plasma norepinephrine levels both on the short-term and after 6 weeks. In another study van Veldhuisen et al. (17) also showed in patients with moderately severe congestive heart failure, which all received converting enzyme inhibitors and diuretics, and most digoxin too, that after 6 weeks of ibopamine plasma norepinephrine levels at peak exercise were lower. So, both in healthy volunteers during exercise and in patients with moderate to severe congestive heart failure at rest and during exercise ibopamine results in a blunted rise of plasma norepinephrine levels. This supported the contention that ibopamine has D2 dopaminergic effects sufficiently outspoken to be apparent in healthy volunteers in conditions of SNS activation like exercise, and in patients with congestive heart failure, whose SNS is already activated, even in resting plasma norepinephrine levels. In a larger study by van Veldhuisen, in patients 18-75 years old with clinically stable class II-III NYHA congestive heart failure with a background treatment of furosemide only up to doses of maximally $80 \mathrm{mg}$, ibopamine was compared to digoxin and placebo (18). One hundred and eighty patients were randomised to doubleblind treatment for 6 months with ibopamine 100 $\mathrm{mg}$ three times daily, digoxin $0.25 \mathrm{mg}$ daily or placebo. Short-acting nitrates were also allowed, as was triamterene, but ACE-inhibitors were not. Duration of exercise time in an exercise test was the primary measure of effect, but secondary end points included scores for symptoms of heart failure, effects on neurohumoral variables and on 24-h ambulatory arrhythmias. Nineteen patients were omitted from the primary analysis because they in fact did not fulfill all the entry criteria, and of the remaining 160 patients 128 completed the treatment period and could be evaluated for all the end points. The results for the primary end point, exercise time, both in an intention-to-treat analysis and an analysis of those who completed the study, showed in fact only just one significant difference, between digoxin and placebo for the intention-totreat analysis after 6 months. In all other comparisons, there was an overlap in confidence intervals. 
The results were more favorable for ibopamine in the heart failure score and the VAS score by the patients. In subgroups, those with a relatively good ejection fraction, those with a low renin or aldosterone value, or those without ventricular tachycardia at baseline did better with ibopamine in the exercise test, while digoxin had a more favorable effect especially in the subgroup with a low ejection fraction. For baseline plasma norepinephrine levels the same trend was observed, but this was not significant. As for the change in resting plasma norepinephrine levels in the three treatment groups, ibopamine compared with placebo, and also with the baseline values, lowered plasma norepinephrine levels. The reduction in plasma norepinephrine levels was found to be related to the baseline levels. Interestingly, ibopamine like digoxin also lowered renin levels.

It has long been known that lower doses of dopamine, up to approximately $5 \mu \mathrm{g} / \mathrm{kg} / \mathrm{min}$, do not affect plasma norepinephrine levels and plasma renin or aldosterone activity at rest. Little is known of its effects under conditions of stimulation of the sympathetic nervous system or renin angiotensin aldosterone system. Lieverse et al. (19) investigated 10 healthy volunteers with two dopamine doses, 1 and $3 \mu \mathrm{g} / \mathrm{kg} / \mathrm{min}$, using the same exercise protocol as in previous studies from our group. The 3 $\mu \mathrm{g} / \mathrm{kg} / \mathrm{min}$ dopamine dose was combined with oral domperidone pretreatment. No difference in baseline plasma norepinephrine levels was observed between the different days. Dopamine $1 \mu \mathrm{g} / \mathrm{kg} / \mathrm{min}$ impaired the rise in plasma norepinephrine levels during exercise while dopamine $3 \mu \mathrm{g} / \mathrm{kg} / \mathrm{min}$ did not (cumulative increase in plasma norepinephrine levels $14.1+/-2.1 \mathrm{nmol} / \mathrm{l}$ for $1 \mu \mathrm{g} / \mathrm{kg} / \mathrm{min}$ dopamine, placebo $20.7+/-2.1$, dopamine $3 \mu \mathrm{g} / \mathrm{kg} / \mathrm{min}$ $20.3+/-1.5 \mathrm{nmol} / \mathrm{l})$. With the combined administration of oral domperidone and dopamine 3 $\mu \mathrm{g} / \mathrm{kg} / \mathrm{min}$ infusion the increase of plasma norepinephrine levels was enhanced at workloads of 60,70 and $80 \%$. It is important to know that no differences were found between the study days in the baseline or exercise values of blood pressure and heart rate. So, it was apparent that there is an inhibitory effect of dopamine on the increase in plasma norepinephrine levels during exercise, but that this is limited to specific doses of dopamine. One may object that norepinephrine release should have been measured in a more direct way, for example with extraction studies with tritium-labeled norepinephrine. An alternative explanation for these results might be that dopamine or the dopaminergic drugs affected flow in the arm. However, this is unlikely due to the fact that it was the lower dose of dopamine which affected the plasma norepinephrine levels, while this dose will have had less outspoken effects on flow. The results of the combined study with dopamine and domperidone also do not fit a flow-dependent explanation. Neuronal or extraneuronal uptake of norepinephrine cannot be excluded. To collect further evidence for the effect of different dopamine doses on the sympathetic nervous system, Lieverse performed an additional study in 10 healthy volunteers in which another stimulus for the sympathetic nervous system was used, i.e. a cold pressor test $(20)$. The vasoconstriction which also occurs during the cold pressor test instead of the vasodilation associated with the exercise test, allows to some extent to eliminate the changes in flow as an alternative explanation for the observed effects on plasma norepinephrine levels. In this case, the 1 and $3 \mu \mathrm{g} / \mathrm{kg} / \mathrm{min}$ dopamine doses were used again, and both doses also in combination with pretreatment with domperidone. No differences were found between the baseline levels. Again, dopamine $1 \mu \mathrm{g} / \mathrm{kg} / \mathrm{min}$ blunted the rise in plasma norepinephrine levels occurring during the cold pressor test. This was abolished when dopamine was combined with domperidone. Besides, dopamine $1 \mu \mathrm{g} / \mathrm{kg} / \mathrm{min}$ either with or without domperidone resulted in lower plasma norepinephrine levels compared to the dopamine $3 \mu \mathrm{g} / \mathrm{kg} / \mathrm{min}$ dose. No difference was found between the placebo study and dopamine $3 \mu \mathrm{g} / \mathrm{kg} / \mathrm{min}$. On the dopamine 1 $\mu \mathrm{g} / \mathrm{kg} / \mathrm{min}$ day a lower systolic blood pressure was found than on the dopamine $3 \mu \mathrm{g} / \mathrm{kg} / \mathrm{min}$ day. Thus, again a dose-dependent effect of dopamine on plasma norepinephrine levels was found. So, comparable results with dopamine were found during two stimuli of the sympathetic nervous system, which are quite different not only in the stimulus itself, and in the associated vasoconstriction and vasodilation respectively, but also in the degree of stimulation. Plasma norepinephrine levels are up to 10 times higher during exercise. This and the fact that the same dose dependency for dopamine was present, in our opinion strongly suggests that we deal with a modulatory effect of dopamine on the SNS. One can only speculate why the $3 \mu \mathrm{g} / \mathrm{kg} / \mathrm{min}$ dose lacks the inhibitory effect: perhaps it has to do with the additonal alpha- or beta-adrenergic effects of dopamine, or with conversion of dopamine to norepinephrine with the high levels of circulating dopamine. Of course additional alpha 2 adrenergic effects for the higher dose should on the contrary have enhanced the inhibitory effect. Perhaps uptake1 inhibition plays a role. So, in conclusion dopamine has a balanced and dose-dependent effect on the SNS activity. This modulation is already evident for endogenous dopamine as first shown by Mannelli. But it becomes clinically even more important when exogenous dopamine or dopamine agonists are used chronically: D2 receptors prevent norepinephrine release by the compensatory SNS activation when D1 effects result in vasodilation.

\section{Bidirectonal Regulation of Renal Tubular Effects of Dopaminergic and Alpha-Adrenergic Stimulation}

Several years ago Smit et al. observed that both the alpha-adrenergic antagonists phentolamine and prazosin impaired or even abolished the natriuretic effect of dopamine infusions, even when the renal hemodynamic effects of dopamine were not affected by either of them $(21,22)$. Recently, Ibarra et al. (23) demonstrated in isolated permeabilized rat renal tubule cells, that the ability of dopamine and 

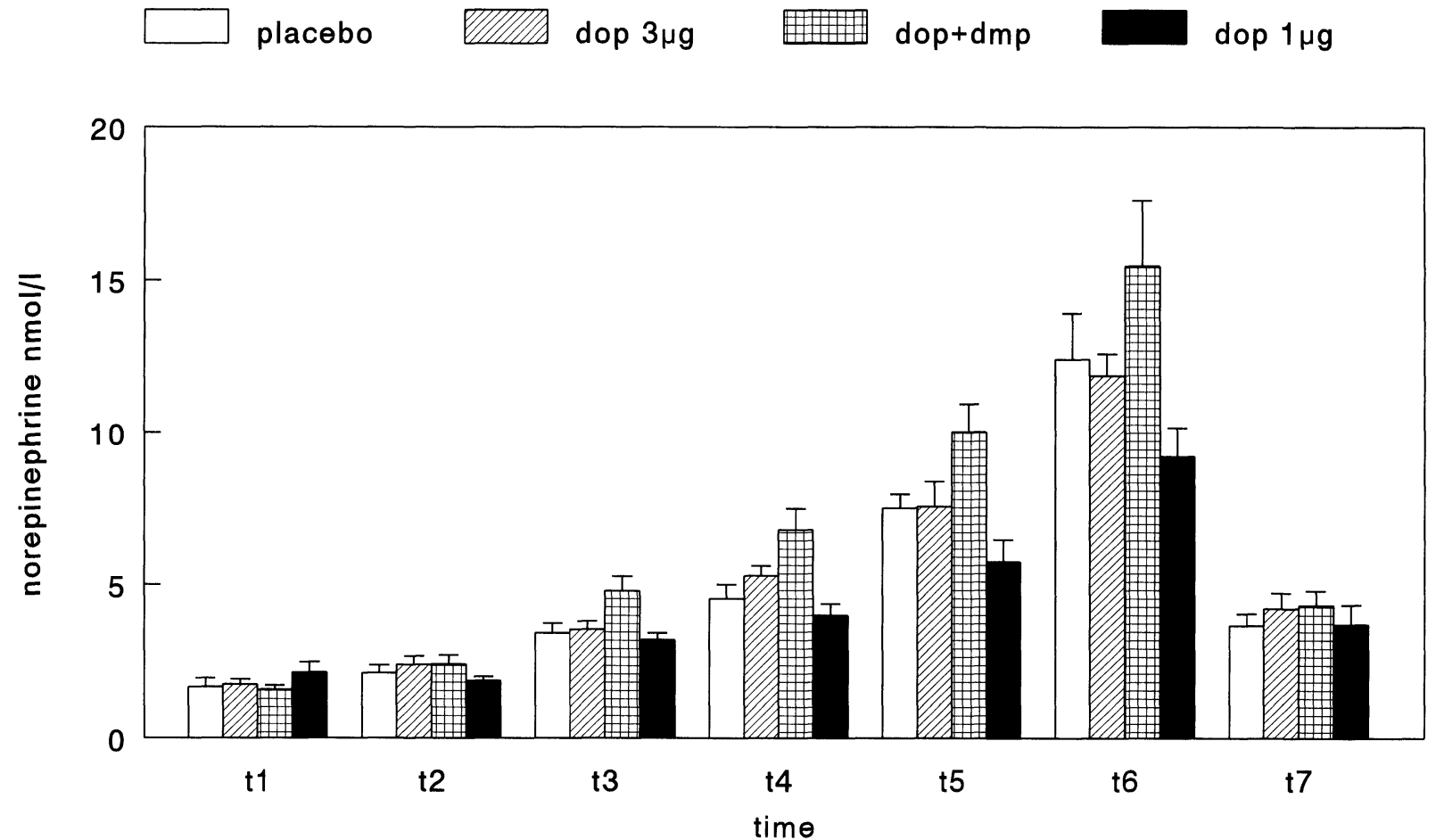

Fig. 1. Plasma norepinephrine levels (nmolll), at rest, at the end of different levels of exercise (expressed as \% of $V_{\mathrm{O}_{2}}$ max), and at the end of recovery, on the study days. Placebo=placebo infusion study day; Dop 1 rg = on dopamine $1 \mu \mathrm{g} / \mathrm{kg} / \mathrm{min}$ infusion study day; Dop $3 \mu \mathrm{g}=$ on dopamine $3 \mu \mathrm{g} / \mathrm{kg} / \mathrm{min}$ infusion study day; Dop/dmp =on study day with infusion of dopamine $3 \mu \mathrm{g} / \mathrm{kg} / \mathrm{min}$, combined with pretreatment with oral domperidone $30 \mathrm{mg}$. ${ }^{*}$ significant difference with placebo infusion day, $\mathrm{p}<0.05$.

alpha adrenergic agonists to regulate $\mathrm{Na}^{+}, \mathrm{K}^{+}$ATPase activity is affected by the concentration of $\mathrm{Na}^{+}$as well as by the absence or presence of the opposing catecholamine. Dopamine was unable to affect $\mathrm{Na}^{+}, \mathrm{K}^{+}$-ATPase activity of isolated tubule segments at physiological concentrations of $\mathrm{Na}^{+}$, unless the alpha adrenergic agonist oxymetazoline was present. In other words, basal adrenergic activity is required for the natriuretic effect of dopamine to become evident. Using the calcium ionophore A23187 instead of oxymetazoline, comparable results were obtained. This supports the contention that this interaction between dopamine and the alpha adrenergic receptor agonist oxymetazoline takes place through a calcium-dependent protein phosphatase. Ibarra also studied this possible interaction between dopamine and norepinephrine in intact rats. The dopamine-1 agonist fenoldopam enhanced sodium excretion from innervated kidneys in euvolemic animals, but this effect of fenoldopam was abolished when the release of norepinephrine from renal nerves was prevented by denervation. Perhaps the abolition of dopamine-induced natriuresis by phentolamine or prazosin in man is an example that the interaction at the level of renal tubular $\mathrm{Na}^{+}, \mathrm{K}^{+}$-ATPase may also be observed in a clinically relevant interaction.

\section{Conclusion}

Dopamine agonists are increasingly used in the chronic treatment of congestive heart failure. The positive effects of ACE-inhibitors on survival in patients with congestive heart failure, and the negative effects on survival with some phosphodiesterase inhibitors, even when they are comparable in their vasodilatory effect, have drawn attention to the socalled neurohumoral effects of drugs used in the treatment in congestive heart failure (24-26). Whereas phosphodiesterase inhibitors may enhance the stimulation of the sympathetic nervous system and renin angiotensin aldosterone system in congestive heart failure, ACE-inhibitors blunt the effects of such a stimulation. Turning to dopamine and dopamine agonists, the D1 dopamine receptor stimulation results in vasodilation, but this may be accompanied by direct and indirect activation of the sympathetic nervous system and renin angiotensin aldosterone system, as evidenced by the results in man with fenoldopam $(3,4)$. Results of long-term fenoldopam treatment have been disappointing in patients with congestive heart failure (unpublished observations). On the other hand, D2 dopamine receptor stimulation is able to limit such an activation by the dopaminergic modulatory effects discussed in this review. If we want orally active dopamine agonists to obtain a more important place in the 
treatment of congestive heart failure, one or more of the following strategies should be followed: to assess the neurohumoral effects of long-term treatment with D2 dopamine agonists in congestive heart failure; to combine a vasodilatory active dopamine agonist with an ACE-inhibitor, preferably in patients with congestive heart failure; to develop and assess the clinical effects of a combined D1/D2 dopamine agonist, without adrenergic effects.

\section{References}

1. Rump LC, Schwertfeger E, Schuster MJ, Schaible U, Frankenschmidt A, Schollmeyer PJ: Dopamine DA2receptor activation inhibits noradrenaline release in human kidney slices. Kidney Int 1993; 43: 197-204.

2. Rump LC, Schwertfeger E, Schaible U, Schuster MJ, Frankenschmidt A, Schollmeyer PJ: Dopamine receptor modualtion of noradrenaline release by carmoxirole in human cortical kidney slices. Eur J Clin Pharmacol 1993; 44: S47-S49.

3. Girbes ARJ, Smit AJ, Meijer S, Reitsma WD: Renal and endocrine effects of fenoldopam and metoclopramide in normal man. Nephron 1990; 56: 179-185.

4. Elliott WJ, Weber RR, Nelson KS, et al: Renal and hemodynamic effects of intravenous fenoldopam versus nitroprusside in severe hypertension. Circulation 1990; 81: 970-977.

5. Szabo B, Crass D, Starke K: Effect of the dopamine $\mathrm{D} 2$ receptor agonist quinpirole on renal sympathetic nerve activity and renal norepinephrine spillover in anesthetized rabbits. J Pharmacol Exp Ther 1992; 263: 806-815.

6. Roquebert J, Moran A, Demichel P: Effect of quinpirole on neurogenic vasoconstriction in the in situ autoperfused hindquarters and renal vascular beds of the rat. J Auton Pharmacol 1992; 12: 291-298.

7. Carratu MR, Camerino DC, De Serio A, Ferrari E, Mitolo-Chieppa D: Pre-junctional regulation of sympathetic neurotransmission in the mouse vas deference: assessment of agonist and antagonist potencies. J Auton Nerv Syst 1990; 30: S35-S37.

8. Carey RM, Van Loon GR, Baines AD, Kaiser DL: Suppression of basal and stimulated noradrenergic activities by the dopamine agonist bromocriptine in man. J Clin Endocrinol Metab 1983; 56: 595-598.

9. Ziegler MG, Lake CR, Williams AC, Teychenne PF, Shoulson I, Stenisland O: Bromocriptine inhibits norepinephrine release. Clin Pharmacol Ther 1979; 25: $137-141$.

10. Lokhandwala MF, Steenberg ML: Evaluation of the effects of SKF 82526 and LY 171555 on presynaptic (DA2) and postsynaptic (DA1) dopamine receptors in rat kidney. J Auton Pharmacol 1984; 4: 273-277.

11. Langer SZ: Presynaptic regulation of the release of catecholamines. Pharmacol Rev 1981; 32: 337-367.

12. Mannelli M, Pupilli C, Fabbri G, et al: Endogenous dopamine (DA) and DA2 receptors: a mechanism limiting excessive sympathetic-adrenal discharge in humans. J Clin Endocrinol Metab 1988; 66: 626-631.

13. Smedes F, Kraak JC, Poppe H: Simple and fast solvent extraction system for selective and quantitative isolation of adrenaline, noradrenaline and dopamine from plasma and urine. J Chromatogr 1982; 231: 2539.

14. Girbes ARJ, Veldhuisen DJ van, Grevink RM, Smit AJ, Reitsma WD: Effects of ibopamine on exerciseinduced increases of norepinephrine in normal man. J Cardiovasc Pharmacol 1992; 19: 371-374.

15. Girbes ARJ, Veldhuisen DJ van, Smit AJ, DrentBremer A, Meijer S, Reitsma WD: Renal and neurohumoral effects of ibopamine and metoclopramide in normal man. Br J Clin Pharmacol 1991; 31: 701-704.

16. Veldhuisen DJ van, Crijns HJ, Girbes ARJ, Tobe TJM, Wiesfeld ACP, Lie KI: Electrophysiologic profile of ibopamine in patients with congestive heart failure and ventricular tachycardia and relation to its effects on on hemodynamics and plasma catecholamines. Am J Cardiol 1991; 68: 1194-1202.

17. Veldhuisen DJ van, Girbes ARJ, Broek SAJ van den, Graeff PA de, Gilst WH van, Lie KI: Effects of ibopamine on the increase in plasma norepinephrine levels during exercise in congestive heart failure. $\mathrm{Am}$ J Cardiol 1992; 71: 992-994.

18. Veldhuisen DJ van, Man in't Veld AJ, Dunselman PHJM, et al: Double-blind placebo-controlled study of ibopamine and digoxin in patients with mild to moderate heart failure: results of the Dutch Ibopamine Multicenter Trial (DIMT). J Am Coll Cardiol 1993; 22: 1564-1573.

19. Lieverse AG, Girbes ARJ, Smit AJ, Reitsma WD: The effects of dopamine and domperidone on exercise-induced increases in norepinephrine in normal man. Neth J Med 1993; 42: A110.

20. Lieverse AG, Lefrandt JD, Girbes ARJ, Smit AJ, Reitsma WD: The effects of different doses of dopamine and domperidone on increases of plasma norepinephrine induced by cold pressor test in normal man. Hypertens Res 1995; 18: elsewhere in this issue.

21. Smit AJ, Meijer S, Wesseling H, Donker AJM, Reitsma WD: Dissociation of renal vasodilatory and natriuretic effects of dopamine during sulpiride infusion in normal man. Eur J Clin Pharmacol 1990; 39: 221-226.

22. Smit AJ, Meijer S, Wesseling H, Donker AJM, Reitsma WD: The effects of alpha-blockade on dopamine-induced renal vasodilation and natriuresis. Naunyn Schmiedebergs Arch of Pharmacol 1991; 343: 143-148.

23. Ibarra F, Aperia A, Svensson L-B, Eklof A-C, Greengard P: Bidirectional regulation of of $\mathrm{Na}^{+} \mathrm{K}^{+}$. ATPase activity by dopamine and an alphaadrenergic agonist. Proc Natl Acad Sci USA 1993; 90: 21-24.

24. Cohn JN, Johnson G, Ziesche S, et al: A comparison of enalapril with hydralazine-isosorbide dinitrate in the treatment of chronic congestive heart failure. $N$ Engl J Med 1991; 325: 303-310.

25. Packer M: The neurohumoral hypothesis: a theory to explain the mechanism of disease progression in heart failure. J Am Coll Cardiol 1992; 20: 248-254.

26. Packer M, Carver JR, Rodeheffer RJ, et al, for the PROMISE Study Research Group: Effect of oral milrinone on mortality in severe chronic heart failure. $N$ Engl J Med 1991; 325: 1468-1475. 